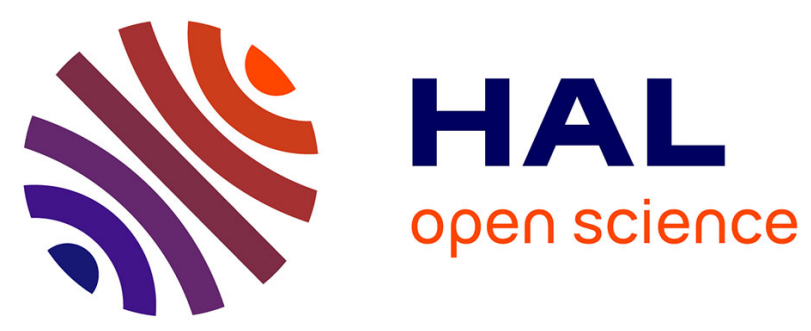

\title{
The concept of frozen elastic energy as a consequence of changes in microstructure morphology
}

Witold Krasny, Claire Morin, Stéphane Avril, Hélène Magoariec, Christian Hellmich

\section{- To cite this version:}

Witold Krasny, Claire Morin, Stéphane Avril, Hélène Magoariec, Christian Hellmich. The concept of frozen elastic energy as a consequence of changes in microstructure morphology. Computer Methods in Biomechanics and Biomedical Engineering, 2015, 18 (S1), pp.1966-1967. 10.1080/10255842.2015.1069581 . hal-01215204

\author{
HAL Id: hal-01215204 \\ https://hal.science/hal-01215204
}

Submitted on 24 Feb 2016

HAL is a multi-disciplinary open access archive for the deposit and dissemination of scientific research documents, whether they are published or not. The documents may come from teaching and research institutions in France or abroad, or from public or private research centers.
L'archive ouverte pluridisciplinaire HAL, est destinée au dépôt et à la diffusion de documents scientifiques de niveau recherche, publiés ou non, émanant des établissements d'enseignement et de recherche français ou étrangers, des laboratoires publics ou privés. 


\title{
The concept of frozen elastic energy as a consequence of change in microstructure morphology
}

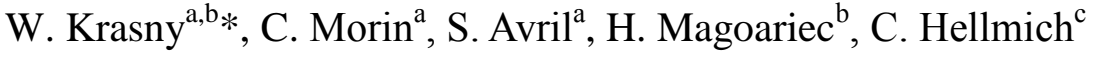 \\ ${ }^{a}$ Centre for Biomedical and Healthcare Engineering, CNRS UMR 5307, (LGF), Ecole Nationale Supérieure des Mines, \\ Saint-Etienne, France; ${ }^{b}$ Laboratoire de Tribologie et Dynamique des Systèmes, CNRS UMR 5513, Université de Lyon, \\ Ecole Centrale Lyon, France; ' Institute for Mechanics of Materials and Structures, Vienna University of Technology, \\ Austria.
}

Keywords: soft tissue, modelling, multi-scale, microstructure, elastic energy

\section{Introduction}

Constitutive modelling of soft biological tissues has been the topic of abundant literature. These biological tissues, made of variously oriented and crimped fibers embedded in a soft matrix, exhibit a highly nonlinear anisotropic behavior with the ability to sustain large reversible strains. The existing constitutive models are mainly phenomenological hyperelastic models developed at the macroscopic scale (Holzapfel \& Gasser 2000). Experimental mechanical tests performed on soft tissues and coupled to confocal microscopic imaging (Schrauwen et al. 2012) reveal that this nonlinear behavior originates in geometrical changes in the microstructure, such as progressive decrimping and re-alignement of the fibers along the load direction. This confirms the growing need to understand the relationship between phenomena taking place in the microstructure and macroscopic mechanical response; subsequently driving forward multi-scale approaches (Morin \& Hellmich 2014). We here propose to model the reorientation of the fibers within the matrix through extension of the framework of continuum micromechanics (Zaoui 2002) and Eshelby's inclusion problems (Eshelby 1957). We investigate the ability of the proposed model to capture, through microstructure morphology changes, the non-linear mechanical response of soft tissues, the possible path dependence of their response to multiaxial loading, and a remaining frozen elastic energy after complete unloading of the tissue.

\section{Methods}

\subsection{Representative Volume Element of soft tissues}

A representative volume element (RVE) of a soft tissue contains an arrangement of variously oriented, infinitely long elastic fibers embedded in a linear elastic matrix (Figure 1). This RVE is subjected at its boundary to a prescribed homogeneous strain rate history.
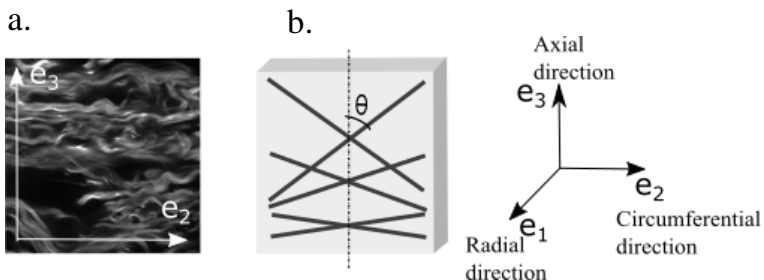

Figure 1a. Collagen bundles of unloaded rabbit carotid artery imaged with confocal bi-photon microscope (IVTV Platform,

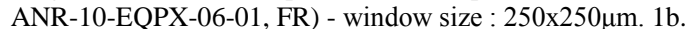
Associated representative volume element and definition of fiber orientation angle $\theta$.

\subsection{Homogenization methodology}

The mechanical response of the RVE is computed within the framework of continuum micromechanics under finite strains by means of an incremental algorithm. The rotation of the fibers is computed by the microscopic second order spin tensor defined as the antisymmetric part of the microscopic velocity gradient. More precisely, extension of the Eshelby problems (Eshelby 1957) allows us to derive semi analytical expressions for what we call "Eshelby rotation operators" and strain concentration tensors. Those operators relate linearly and respectively for each phase the microscopic spin tensor and the microscopic strain rate tensor to the macroscopic imposed strain rate. The latter relations quantify loadinduced micro-configurational changes. The local mechanical responses are then upscaled to the macroscopic scale by use of the stress average rule, providing the derivation of the RVE effective response.

*Corresponding author. Email: witold.krasny@emse.fr 


\subsection{Loading paths}

In order to analyze trajectory dependence and understand how the material absorbs and releases elastic deformation energy in its microstructure, the RVE is loaded by prescribed uniaxial and biaxial velocity paths, realizing closed elastic strain cycles, so as to impose the system to return to its macroscopic undeformed initial state at the end of the cycle.

\section{Results and discussion}

Uniaxial trajectories confirm the ability of the model to qualitatively reproduce the usual non-linear behavior of soft tissues, with progressive stiffening of the response. For multiaxial loadings, a dependence of the system to deformation trajectory is noticed: when unloading is applied following the exact contrary path to loading, fibers return to their exact initial configuration and the macroscopic mechanical state is free of residual stresses: all elastic energy stored in the fibers is released during unloading.

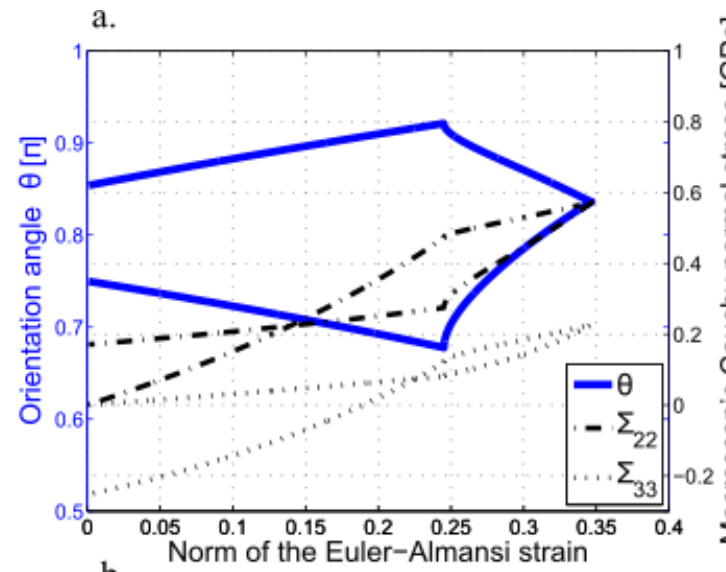
b.

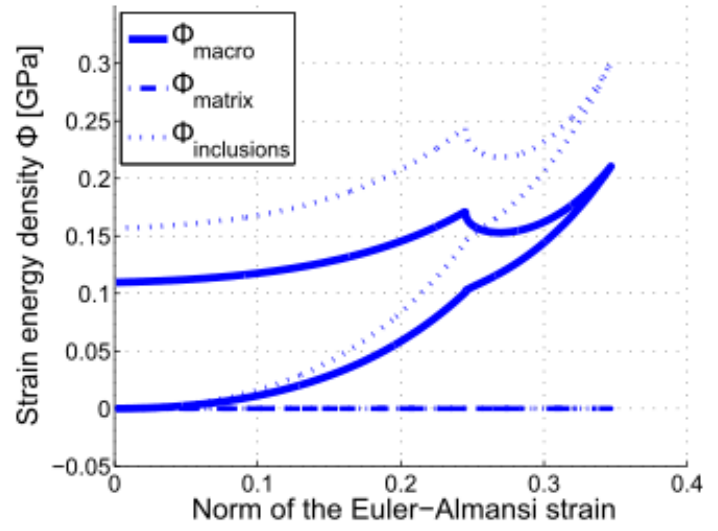

Figure 2. Orientation angle $\theta$ of a given fiber family and macroscopic Cauchy stress (a) and macroscopic and microscopic strain energy densities $\phi$ (b) as functions of the norm of the macroscopic Euler-Almansi strain.
On the contrary when unloading follows a path different to the loading one (for example loading in direction $\mathbf{e}_{2}$ then $\mathbf{e}_{3}$ followed by unloading in directions $\mathbf{e}_{2}$ then $\mathbf{e}_{3}$ as shown in Figure 2), fibers do not reach their initial configuration although the final macroscopic deformation state is forced identical to the initial macroscopic configuration. As a consequence, the macroscopic Cauchy stress does not return to zero (Figure 2a), there is an insufficient release of absorbed elastic energy (observed hysteresis), resulting in final "frozen" elastic energy in the material as a consequence of the change in microstructure morphology (Figure 2b).

\section{Conclusions}

This is the first hypoelastic micromechanical model for soft tissues introducing a limited number of physical parameters. The modeled mechanical behavior exhibits path-dependence of the response and possible frozen elastic energy remaining in the system after complete unloading. This behavior originates in the micro-configurational changes occurring in the microstructure due to the application of loads and resulting in history-dependent configurations of fiber orientations. Future work will focus on the evolution of residual stresses after successive closed deformation loops, and the possible stabilization of residual stress accumulation.

\section{Acknowledgments}

This material is based upon work supported by the ARC2 program of the Rhône-Alpes region (FR) and the AMADEUS bilateral program of Campus France.

\section{References}

Eshelby JD. 1957. The Determination of the Elastic Field of an Ellipsoidal Inclusion, and Related Problems, Proc. Royal Soc. London. A. Math. Phys. Sc. 241(1226):376396.

Holzapfel G, Gasser C. 2000. A New Constitutive Framework for Arterial Wall mechanics and comparative study of material models. J. Elas. 61:1-48.

Morin C, Hellmich C. 2014. A multiscale poromicromechanical approach to wave propagation and attenuation in bone. Ultrasonics. 54:1251-1269.

Schrauwen JTC, Vilanova A, Rezakhaniha R, Stergiopulos N, van den Vosse FN, Bovendeerd PHM. 2012. A method for the quantification of the pressure dependent $3 \mathrm{D}$ collagen configuration in the arterial adventitia. J. Struct. Biol. 180:335-342.

Zaoui A. 2002. Continuum Micromechanics : Survey. J. Eng. Mech. 128(8):808-816. 